\title{
Effects of Treatment Environment and Intensive Nursing Intervention on Gynecological Oncology Patients
}

\author{
Qiufang Zhang, Xinke Huang ${ }^{*}$, Xuefeng Jiang, Manli Huang \\ Gynecology Department, The First Affiliated Hospital of Jinan University, Guangzhou, China \\ Email address: \\ 957773931@qq.com (Qiufang Zhang),929901838@qq.com (Xinke Huang), xuefengjiang@126.com (Xuefeng Jiang), \\ 13826197465@163.com (Manli Huang) \\ *Corresponding author
}

\section{To cite this article:}

Qiufang Zhang, Xinke Huang, Xuefeng Jiang, Manli Huang. Effects of Treatment Environment and Intensive Nursing Intervention on Gynecological Oncology Patients. Journal of Gynecology and Obstetrics. Vol. 8, No. 1, 2020, pp. 28-31. doi: 10.11648/j.jgo.20200801.17

Received: January 14, 2020; Accepted: January 29, 2020; Published: February 21, 2020

\begin{abstract}
Objective: To assess effects of treatment environment and intensive nursing intervention on gynecological oncology patients. Methods: 108 patients diagnosed as gynecological oncology from July 2015 to July 2018 . They were randomly assigned to control group and intervention group, the participant had the different nursing measure and new treatment environment in two groups. We collected the result that included quality of life, pain level, immune function and participants characteristics by completing questionnaires, collecting medical records and flow cytometer. In addition, the participants were asked to complete the questionnaires, such as Short Form-36 (SF-36) and Self-report questionnaires. We use flow cytometer (FCM) to assess immunity function of patient. Result: The participants of intervention group had higher increasing in $\mathrm{CD}_{8}{ }^{+}(19.88 \pm 2.40$ vs 17.32 \pm 2.88 ). Additionally, most participants had mild pain in treatment process [30 (50.66\%) \& $42(73.24 \%)]$ and few participants had severe pain. In addition, few participants had severe pain, very few participants had very pain experience and painless experience in treatment process. In four domains of quality of life, all participants were improved in all domains. Conclusion: Treatment environment and intensive nursing intervention improve the outcome of gynecologic cancer treatment. But the improvement was not significant in the treatment process.
\end{abstract}

Keywords: Gynecological Oncology, Treatment Environment, Nursing

\section{Introduction}

Optimal treatment and care of women with gynaecological cancers requires a multidisciplinary team, such as gynaecological oncologists; medical oncologists; radiation oncologists; nurses with specialist gynaecological expertise; pathologists; radiologists; general practitioners; gynaecologists; specialist allied health professionals; palliative care providers; sexual health counsellors; geneticists; dieticians; and genetic counsellors [1, 2]. As some reports, Specialist nurses are considered important members of gynaecological cancer multidisciplinary teams providing comprehensive treatment of gynaecological cancers [3, 4]. Additionally, gynecologic oncologists' daily practice involves situations that require complex communication skills, including disclosing serious news and discussion of prognosis, treatment decisions, and goals of care $[5,6]$.

Compared to other female surgical patients, women with gynecologic cancers are more likely older and obese, they need complex care, they had higher risk for hospital readmission after surgery [7-10]. Following to the report of single academic institution, readmission rate was $13.2 \%$ on a gynecologic oncology service, they had few planned readmissions that the mean cost of readmission was $\$ 9820$ per time [11]. This study aim was evaluate effects of treatment environment and intensive nursing intervention on gynecological oncology patients, to reduce readmission rate and to improve the outcome of gynaecological oncologists treatment.

\section{Methods}

\subsection{Participants Enrollment and Survey Methods}

The patients $(\mathrm{n}=108)$ were investigated to join our study who were diagnosed as gynaecological cancers, their age were 
between 20 and 50 . We collected the related data of patients which was from July 2015 to July 2018. In addition, the participants were randomly assigned to two group, such as intervention group $(\mathrm{n}=54)$ and control group $(\mathrm{n}=54)$. In intervention group, we changed the treatment environment and nursing measure to the participants, our researchers would record the outcome of treatment. In control group, we use traditional treatment environment and traditional nursing measure for the participants. The participants were asked to complete the questionnaires, such as Short Form-36 (SF-36) and Self-report questionnaires [12, 13]. Additionally, we use flow cytometer (FCM) to assess immunity function of patient.

Their inclusion criteria were: (1) the patients were diagnosed as gynaecological cancers; (2) people volunteered to participate in postoperative follow-up; (3) Cognitively and mentally were normal. Their withdraw criteria were: (1) mental health was not good; (2) the patients had many complications; (3) the patients had metastasis of cancer.

\subsection{Statistical Analysis}

We use SPSS24.0. to analyze and assess the data. We used P value, t-test and chi-square test to analyze the collection outcome. Additionally, the mean standard deviation for statistical description.

\section{Result}

We collected the data associated with participants characteristics when they join our study (Table 1). Most of their cancer type were cervical cancer in both of groups [15 (25.97\%) \& 16 (30.58\%)]. Additionally, all of cancer type had statistical significance $(\mathrm{p}<0.005)$.

Table 1. Participants Characteristics.

\begin{tabular}{|c|c|c|c|c|}
\hline Projects & Intervention Group, n (\%) & Control Group, n (\%) & $\mathbf{X}^{2}$ & P value \\
\hline \multicolumn{5}{|l|}{ Cancer types } \\
\hline Ovarian cancer & $9(15.12 \%)$ & $8(11.79 \%)$ & \multirow{5}{*}{2.582} & \multirow{5}{*}{$<0.005$} \\
\hline Cervical cancer & $15(25.97 \%)$ & $16(30.58 \%)$ & & \\
\hline Malignant tumor of fallopian tube & $7(15.44 \%)$ & $5(10.12 \%)$ & & \\
\hline Endometrial cancer & $8(9.77 \%)$ & $7(15.04 \%)$ & & \\
\hline choriocarcinoma & $9(13.23 \%)$ & $8(12.88 \%)$ & & \\
\hline \multicolumn{5}{|l|}{ Marital status } \\
\hline Married & $44(83.65 \%)$ & $48(86.07 \%)$ & \multirow{2}{*}{1.259} & \multirow{2}{*}{0.355} \\
\hline Unmarried & $9(17.03 \%)$ & $7(11.18 \%)$ & & \\
\hline Weight (Kg) & $60.77 \pm 8.03$ & $59.40 \pm 8.68$ & 3.2 & 0.221 \\
\hline Age (Years) & $40.06 \pm 3.53$ & $39.35 \pm 2.97$ & 0.281 & 0.281 \\
\hline Course of the disease (Months) & $5.56 \pm 1.28$ & $5.27 \pm 1.21$ & 0.704 & 0.704 \\
\hline
\end{tabular}

In immune function, the participants of intervention group had higher increasing in $\mathrm{CD}_{8}{ }^{+}(19.88 \pm 2.40 \mathrm{vs} 17.32 \pm 2.88)$. In addition, the participants of control group had higher increasing in another projects, that included $\mathrm{CD}_{3}{ }^{+}, \mathrm{CD}_{4}{ }^{+}$and NK. The $\mathrm{CD}_{8}{ }^{+}$, $\mathrm{CD}_{4}{ }^{+}$and NK had statistical significance $(\mathrm{p}<0.005)$ (Table 2$)$.

Table 2. The immune function of participant.

\begin{tabular}{llllllll}
\hline \multirow{2}{*}{ Projects } & \multicolumn{2}{l}{ Intervention Group } & \multicolumn{3}{l}{ Control Group } \\
\cline { 2 - 8 } & BN & FN & T & P value & BN & FN & T \\
\hline $\mathrm{CD}_{3}^{+}$ & $63.76 \pm 9.01$ & $80.22 \pm 12.34$ & 7.013 & $<0.005$ & $66.25 \pm 6.04$ & $84.37 \pm 15.04$ & 6.951 \\
$\mathrm{CD}_{4}^{+}$ & $33.29 \pm 5.32$ & $46.78 \pm 4.69$ & 12.305 & $<0.005$ & $31.68 \pm 4.25$ & $55.36 \pm 6.16$ & 20.664 \\
$\mathrm{CD}_{8}^{+}$ & $24.28 \pm 3.26$ & $19.88 \pm 2.40$ & 8.041 & $<0.005$ & $26.09 \pm 2.94$ & $17.32 \pm 2.88$ & 18.127 \\
$\mathrm{NK}$ & $13.06 \pm 1.88$ & $26.30 \pm 2.26$ & 27.024 & 0.43 & $14.93 \pm 2.06$ & $34.44 \pm 2.23$ & 39.757 \\
\hline
\end{tabular}

$\mathrm{BN}=$ Before the Nursing.

$\mathrm{FN}=$ After the Nursing.

The pain assessment was collected by Self-report questionnaires. Most participants had mild pain in treatment process [30 $(50.66 \%) \& 42(73.24 \%)]$. Few participants had severe pain, very few participants had very pain experience and painless experience in treatment process (Table 3).

Table 3. Pain Assessment.

\begin{tabular}{|c|c|c|c|c|}
\hline Projects & Painless & Mild Pain & Severe Pain & Very Pain \\
\hline Control Group, n (\%) & $1(1.79 \%)$ & $30(50.66 \%)$ & $18(36.03 \%)$ & $5(6.83 \%)$ \\
\hline Intervention Group, $\mathrm{n}(\%)$ & $2(4.96 \%)$ & $42(73.24 \%)$ & $8(15.11 \%)$ & $2(2.97 \%)$ \\
\hline
\end{tabular}

The quality of life of participants was collected by SF-36. In four domains of quality of life, all participants were improved in all domains. The participants of intervention group had better improvement than the participants of control group in 4 domains (Table 4). Besides, the data of 4 domains had statistical significance. 
Table 4. Quality of Life.

\begin{tabular}{|c|c|c|c|c|c|c|}
\hline \multirow{2}{*}{ Projects } & \multicolumn{2}{|c|}{ Control Group } & \multicolumn{2}{|c|}{ Intervention Group } & \multirow{2}{*}{$\mathbf{T}$} & \multirow{2}{*}{ P value } \\
\hline & BN & FN & BN & FN & & \\
\hline Psychological Function (Mean \pm SD) & $29.69 \pm 3.22$ & $32.03 \pm 5.71$ & $29.95 \pm 3.09$ & $35.76 \pm 5.28$ & 18.266 & $<0.005$ \\
\hline Body Function $($ Mean \pm SD) & $21.43 \pm 3.84$ & $23.07 \pm 3.48$ & $22.33 \pm 2.63$ & $26.14 \pm 4.16$ & 23.420 & $<0.005$ \\
\hline Social Function $($ Mean \pm SD) & $19.90 \pm 2.88$ & $23.98 \pm 4.32$ & $20.34 \pm 2.07$ & $26.83 \pm 5.02$ & 23.781 & $<0.005$ \\
\hline Common Symptoms and Side Effects (Mean \pm SD) & $24.81 \pm 3.06$ & $28.14 \pm 4.41$ & $23.97 \pm 1.94$ & $29.78 \pm 4.05$ & 26.083 & $<0.005$ \\
\hline
\end{tabular}

$\mathrm{BN}=$ Before the Nursing.

$\mathrm{FN}=$ After the Nursing.

\section{Discussion}

Gynecologic cancer is the third leading cause of cancer-related deaths for women in the United States [14]. Ovarian cancer results in an estimated 13,980 deaths a year in the United States, and remains a malignancy with one of the poorest prognoses, a 5-year survival of approximately $35 \%$. Uterine cancers, while faring more favorably overall, are estimated to result in 12,160 deaths a year and those with advanced staged or recurrent disease have a 5- year survival of $17 \%[15,16]$. Following to some reports, gynecologic cancer remains one of the few cancers with an increasing incidence rate and overall mortality $[17,18]$.

According to outcome of our research, treatment environment and intensive nursing intervention can slight change the outcome of gynecologic cancer treatment. In immune function research, the improvement between the two groups had not significant effect. However, the improvement of treatment environment and intensive nursing intervention was significant. In intervention group, most of participants were mild pain level in the treatment process. The participant of control group had most in severe pain level. So the intervention group had better result than control group in the pain status of participant. Similarly, in the score of QoL, the intervention group had higher score than control group in 4 domains of QoL. Additionally, all domain of Qol had statistical significance.

\section{Conclusion}

In conclusion, treatment environment and intensive nursing intervention improve the outcome of gynecologic cancer treatment. But the improvement was not significant in the treatment process. In pain level of participant, the new treatment environment and new nursing measure ease the part of participant's pain. In QoL, participants of intervention group had higher score of QoL in 4 domains. However, sample size was limitations in the study, it limit degree of accuracy of result.

\section{References}

[1] Cancer Australia \& The Royal Australian College of Obstetricians and Gynaecologists. National Gynaecological Cancer Service Delivery and Resource Framework. Cancer Australia, Canberra, Australia. 2011.
[2] National Gynaecological Cancer Tumour Standards Working Group. Standards of Service Provision for Gynaecological Cancer Patients in New Zealand. New Zealand Ministry of Health, Wellington. 2013.

[3] Fung-Kee-Fung, M., Kennedy, E. B., Biagi, J., Colgan, T., D'Souza, D., Elit, L. M., et al. An organizational guideline for gynecologic oncology services. Int. J. Gynecol. Cancer. 2015; 25 (4): 551-558.

[4] NHS Commissioning Board. NHS Contract for Complex Gynaecology-Specialist Gynaecologocial Cancers. Service Specifications. NHS Commissioning Board. 2013.

[5] Wright A. A., Zhang B., Ray A., Mack J. W., Trice E., Balboni T., et al., Associations between end-of-life discussions, patient mental health, medical care near death, and caregiver bereavement adjustment, JAMA. 2008; (14): 1665-1673.

[6] Mack J. W., Weeks J. C., Wright A. A., Block S. D., Prigerson H. G. End-of-life discussions, goal attainment, and distress at the end of life: predictors and outcomes of receipt of care consistent with preferences, J. Clin. Oncol. Off. J. Am. Soc. Clin. Oncol. 2010; 28 (7): 1203-1208.

[7] Fader A. N., Weise R. M., Sinno A. K., Tanner E. J., Borah B. J., Moriarty J. P., Bristow R. E., Makary M. A., Pronovost P. J., Hutfless S., Dowdy S. C., Utilization of minimally invasive surgery in endometrial cancer care: a quality and cost disparity, Obstet. Gynecol. 2016; 127 (1): 91-100.

[8] Clark R. M., Lee M. S., Rauh-Hain J. A., Hall T., Boruta D. M., del Carmen M. G., A. K. Goodman, J. O. Schorge, W. B. Growdon, Surgical Apgar score and prediction of morbidity in women undergoing hysterectomy for malignancy, Gynecol. Oncol. 2015; 136: 516-520.

[9] Dessources K., Hou J. Y., Tergas A. I., Burke W. M., Ananth C. V., Prendergast E., Chen L., Neugut A. I., Hersham D. L., Wright J. D. Factors associated with 30-day hospital readmission after hysterectomy, Obstet. Gynecol. 2015; 2: 461-470.

[10] Doll K. M., Snavely A. C., Kalinowski A., Irwin D. E., Bensen J. T., Bae-Jump V., Boggess J. F., Soper J. T., Brewster W. R., Gehrig P. A. Preoperative quality of life and surgical outcomes in gynecologic oncology patients: a new predictor of operative risk, Gynecol. Oncol. 2015; 133: 546-551.

[11] Henretta M. S., Scalici J. M., Engelhard C. L., Duska L. R. The revolving door: hospital readmissions of gynecologic oncology patients, Gynecol. Oncol. 2011; 122: 479-483.

[12] Ware JE. SF-36 health survey update. Spine. 2000, 25, 3130 3139 .

[13] Brunner E, Dankaerts W, Meichtry A, O'Sullivan K, Probst M: Physical therapists' ability to identify psychological factors and their self-reported competence to manage chronic low back pain. Phys Ther. 2018; 98: 471-479. 
[14] Siegel RL, Miller KD, Jemal A. Cancer statistics, 2019. CA Cancer J Clin. 2019; 69: 7-34.

[15] Jayson GC, Kohn EC, Kitchener HC, Ledermann JA. Ovarian cancer. Lancet. 2014; 384: 1376-1388.

[16] Makker V, Green AK, Wenham RM, Mutch D, Davidson B, Miller DS. New therapies for advanced, recurrent, and metastatic endometrial cancers. Gynecol Oncol Res Pract. 2017; 4: 19 .
[17] Henley SJ, Miller JW, Dowling NF, Benard VB, Richardson LC. Uterine Cancer Incidence and Mortality - United States, 1999-2016. MMWR Morb Mortal Wkly Rep. 2018; 67: 1333-1338.

[18] Jemal A, Ward EM, Johnson CJ, Cronin KA, Ma J, Ryerson AB, Mariotto A, Lake AJ, Wilson R, Sherman RL, Anderson RN, Henley SJ, Kohler BA, Penberthy L, Feuer EJ, Weir HK. Annual Report to the Nation on the Status of Cancer, 19752014, Featuring Survival. JNCI: Journal of the National Cancer Institute. 2017; 109. 